\title{
LOS DERECHOS DE LOS VENCIDOS: LAS CAPITULACIONES DE GRANADA (1491)
}

\author{
Isabelle Poutrin*
}

Anteriormente a las Cruzadas de Oriente, la tradición jurídica cristiana estableció una diferencia en el tratamiento respectivo de las dos grandes categorías de infieles, los musulmanes y los judíos. En el año 1060, el papa Alejandro II explicó por qué le parecía justo combatir contra los primeros, mientras no había motivo para hacer la guerra a los segundos ya que vivían en una condición de sumisión a los cristianos:

“El caso de los judíos y de los sarracenos es diferente, por cierto. Contra estos, que persiguen a los cristianos y los echan de sus ciudades y de sus tierras, es justo combatir; mientras aquellos están dispuestos a servir en todas partes" ${ }^{\prime 1}$.

Este texto fue inserto por el maestro Graciano en el Decreto al final del siglo XI para formar el capítulo «Dispar» de su gran compilación del derecho canónico. Contribuyó, en los siglos posteriores, tanto a fundar el régimen de tolerancia concedido a los judíos, como a legitimar la guerra contra los musulmanes en general, y la conquista del reino de Granada en particular. Sin embargo, en 1492, al concluir la guerra de Granada, los Reyes Católicos invirtieron el destino de los dos grupos de infieles mencionados en el capítulo «Dispar». Decretaron la expulsión de los judíos, a la sazón considerados como una amenaza contra la fe cristiana. A los musulmanes vencidos les permitieron quedarse en el país a pesar de considerar su presencia como el fruto histórico de una usurpación. En el fondo, estas decisiones no contradecían la doctrina del papa Alejandro II: la diferencia de religión no es, en sí, un motivo para hacer la guerra a los infieles, y los que aceptan vivir pacíficamente en los reinos cristianos, sean judíos o musulmanes, no tienen por qué ser molestados ${ }^{2}$. Los

* Université de Paris-Sorbonne XII.

1. “Dispar nimirum est Judeorum et Sarracenorum causa. In illos enim, qui Christianos persecuntur, et ex urbibus et propiis sedibus pellunt, iuste pugnatur; hii ubique servire parati sunt", Decretum Gratiani, 2. C.23 q.8 c.11. Ver G. DAHAN, Les intellectuels chrétiens et les juifs au Moyen Age (Polémique et relations culturelles en Occident, XIIe-XIVe s.), Paris, Cerf, 1990, p. 138.

2. Sobre la atenuación de la distinción entre judíos y musulmanes, N. ZACOUR, Jews and Saracens in the Consilia of Oldradus de Ponte, Toronto, Pontifical Institute of Maedieval Studies, 1990, p. 17. 
Reyes, que no querían despoblar el reino de Granada, optaron por mantener in situ la población del territorio conquistado. A tal efecto, conservaron el procedimiento que les había permitido acelerar la conquista: las capitulaciones negociadas y firmadas con varias localidades definieron los derechos de los vencidos en un sentido siempre más favorable a estos últimos.

Las capitulaciones que más han llamado la atención de los historiadores son las de la ciudad de Granada, resultado de los tratos con el rey Boabdil, firmadas por los Reyes el 25 de noviembre de 1491. No entraremos aquí en los debates sobre el estatuto jurídico de las capitulaciones (¿pactos contractuales o privilegios revocables a su conveniencia por el príncipe legibus solutus?), o sobre la voluntad (¿sincera o no?) de los Reyes de hacer respetar los artículos ${ }^{3}$. Se suele considerar que los Reyes aceptaron amplias concesiones para terminar la guerra, pero que tal régimen de tolerancia no tenía vocación de mantenerse durante mucho tiempo. Tal es el juicio emitido en 1865 por Francisco Fernández y González:

"Fueron en verdad las capitulaciones de Granada las más favorables de las concedidas a los pueblos de la península, muestra grande de la tolerancia de los Reyes Católicos y del significado y poder que aún tenían los muslimes, bien que por su carácter anormal y extraordinario no se avenían a ser duraderas" ${ }^{\prime 4}$.

La historiografía reciente está conforme con este parecer. Luis Suárez Fernández ve en las capitulaciones de Granada una prueba de la generosidad de los Reyes, ya que acceden a casi todas las peticiones de Boabdil, y que las modificaciones introducidas en el texto definitivo van a favor de los musulmanes. Miguel Ángel Ladero Quesada advierte que la intervención de Cisneros contra los elches (los cristianos convertidos al Islam), en 1499, fue una acción contraria a las mismas capitulaciones ${ }^{5}$. En la misma perspectiva, para José Enrique López de Coca Castañer las capitulaciones establecen "el respecto a las leyes y religión de los vencidos"; pero los Reyes Católicos, al considerar la condición musulmana de sus nuevos vasallos como algo provisional, se alejan del espíritu del texto ${ }^{6}$. También es la conclusión de Ángel Galán Sánchez: "la actuación de Cisneros violaba

3. M.A. LADERO QueSADA, «Los bautismos de los musulmanes granadinos en 1500», en De mudéjares a moriscos: una conversión forzada. Actas del VIII Simposio internacional de mudejarismo, Teruel, Centro de Estudios Mudéjares, 2002, pp. 481-542.

4. F. FERNÁNDEZ y GONZÁLEZ, Estado social y político de los mudéjares de Castilla: considerados en sí mismos y respecto de la civilización española, [1865], Madrid, Libros Hiperión, 1985, p. 200.

5. L. SuÁreZ FERNÁNDEZ, «La conversión de los musulmanes», en L. SuÁrez FernáNDEZ y M. Fernández Álvarez, La España de los Reyes Católicos (1474-1516), vol. 2, Historia de España dirigida por don Ramón Menéndez Pidal, t. XVII, Madrid, Espasa Calpe, 1969, pp. 285-301; M.A. LADERO QuesADA, Granada después de la Reconquista: repobladores y mudéjares, 2. ${ }^{a}$ ed., Granada, Diputación provincial de Granada, 1993, pp. 350-352.

6. J.E. LÓPEZ DE COCA CASTAÑER, «Las capitulaciones y la Granada mudéjar», en M.A. LADERO QuESADA (dir.), La incorporación del reino de Granada a la corona de Castilla, Granada, Diputación provincial de Granada, 1993, p. 297. 
claramente las capitulaciones de la rendición" ${ }^{\prime 7}$. Insistiendo en el carácter provisional de las capitulaciones, Antonio Luis Cortes Peña subraya que "no era intención de los Reyes Católicos perpetuar la situación de dualidad surgida en las capitulaciones, sino la de ganar tiempo" ${ }^{\prime 8}$. La cuestión debatida es, más bien, la de las responsabilidades respectivas de los Reyes y de Cisneros en la política de conversión de los vencidos. Manuel Barrios Aguilera demuestra que, en realidad, tanto el arzobispo Talavera como el arzobispo Cisneros pusieron en obra una línea definida por los propios Reyes, una línea contraria a las capitulaciones que "establecían clara y rotundamente el respeto de la religión de los vencidos"9

No pretendemos discutir la idea de la generosidad de los Reyes en cuanto a las concesiones hechas a los vencidos en el conjunto de las capitulaciones. Pero, fijándonos solamente en sus aspectos religiosos, no suscribimos la tesis de la ruptura, por el afán del arzobispo Cisneros o de los mismos Reyes de obtener la conversión de los musulmanes, de un statu quo establecido por las cláusulas negociadas con Boabdil. Al contrario, nos parece que las condiciones de la rendición estaban lejos de fijar la situación religiosa de los vencidos. Las capitulaciones abrían el paso a una dinámica de conversión de la población musulmana y a la recuperación de los elches por la Iglesia, línea seguida en los años siguientes (aunque con métodos diferentes) tanto por Hernando de Talavera, primer arzobispo de Granada, como por Francisco Jiménez de Cisneros, el arzobispo de Toledo llegado a la ciudad en octubre 1499 por orden de los Reyes, el cual actúa luego en cualidad de inquisidor. En lo que toca a la religión, la generosidad de los Reyes y su actitud de respeto hacia las leyes de los vencidos, al final de 1491, nunca prescinden de los intereses superiores de la fe cristiana. Apoyamos esta propuesta de interpretación sobre la comparación entre las peticiones de Boabdil y el texto de las capitulaciones. Las cláusulas religiosas presentadas por el rey nazarí intentan evitar la inferioridad de los musulmanes bajo la dominación de los cristianos, y mantener la práctica del culto y la transmisión del Islam de padres a hijos. Su redacción, por cierto, implicó la participación de juristas ${ }^{10}$. Veremos que, en su respuesta al rey vencido, los Reyes modificaron cuidadosamen-

7. A. GALÁN SÁNCHEZ, «Las conversiones al Cristianismo de los musulmanes de la Corona de Castilla: una visión teológico-política», en De mudéjares a moriscos: una conversión forzada. Actas del VIII Simposio internacional de mudejarismo, Teruel, Centro de Estudios Mudéjares, 2002, p. 633.

8. A.L. Cortes PeÑA, «Mudejares y moriscos granadinos, una vision dialéctica tolerancia-intolerancia», Granada 1492-1992. Del Reino de Granada al futuro del mundo mediterráneo, Granada, Universidad de Granada, 1995, p. 99, n. 4.

9. M. BARrios Aguilera, Granada morisca. La convivencia negada, Granada, Comares, 2002, p. 67. Ver también B. VINCENT, «Des mudéjares aux morisques (1492-1526)», en E. BELENGUER CEBRIA (coord.), De la unión de coronas al Imperio de Carlos V, vol. 2, Sociedad Estatal para la conmemoración de los centenarios de Carlos V y Felipe II, 2001, pp. 359-370.

10. El estudio de los tratados entre príncipes cristianos y musulmanes es una pista de investigación propuesta por P.S. VAN KONINGSVELD y G.A. WIEGERS, «The Islamic Statute of the Mudejars in the light of a new source», Al Qantara, vol. XVII/1, 1996, p. 54. 
te los puntos que podían poner obstáculo a la dinámica de conversión ${ }^{11}$. Intentaremos medir el alcance de estas modificaciones con las disposiciones del derecho canónico, sobre cada uno de los puntos tratados en estas cláusulas.

\section{LA LLAMADA A LA ORACIÓN}

Unas disposiciones tocan a la libertad, otorgada a los musulmanes, de conservar su religión y de practicar su culto. El texto propuesto por Boabdil resume en sus aspectos esenciales la práctica del Islam, a la vez que observancia cultual materializada por las mezquitas, los alminares y los almuecines, y ordenamiento jurídico cuyos guardianes son los jueces:

“Otrosy, que sean obligados sus altezas y sus descendientes para siempre de dejarlos bivir en su ley y en su xaraçunna, y sus mezquitas, y sus alcadís, y sus almuédanos con sus torres y que les consientan dar vozes á sus almuédanos como solían antes, con sus costumbres" ${ }^{\prime 2}$.

Las capitulaciones desarrollan más ampliamente las condiciones de la práctica del Islam y llaman la atención sobre el marco comunitario de la aljama:

"Item es asentado y concordado que sus Altezas e sus descendientes para siempre jamás dejaran vivir al dicho Rey Muley Bauudili e á los dichos alcaides e alcadís, e sabios, e moftíes, e alfaquíes, e alguaciles, e caballeros e escuderos, e viejos e buenos hombres, e comunidad, chicos e grandes, e estar en su ley, e non les mandaran quitar sus algimas e zumaas, e almuédanos, e torres de los dichos almuédanos, para que llamen á sus azalaes, e dejarán e mandarán dejar á las dichos algimas sus propios e rentas como agora los tienen, e que sean juzgados por su ley xaraçina con consejo de sus alcadís, segund costumbre de los moros, y les guardarán e mandarán guardar sus buenos usos e costumbres"13.

La institución de la aljama se sitúa en continuidad con la situación anterior a la conquista, en lo que toca a la delegación de poderes al cadí, juez y director de la comunidad, así como a los bienes de las mezquitas y al personal religioso. Su mantenimiento facilitó el paso de los musulmanes al estado de grupo minoritario en un Estado cristiano. Este último no tenía inconveniente en aceptar la aplicación del derecho islámico para arreglar los litigios internos de la comuni-

11. Juan Meseguer Fernández sugirió esta comparación de las cláusulas religiosas: J. MESEGUER FERNÁNDEZ, «Fernando de Talavera, Cisneros y la Inquisición en Granada», en J. Pérez VILLANUEVA (dir.), La Inquisición española. Nueva visión, nuevos horizontes, Madrid, Siglo Veintiuno editores, 1980, pp. 396-397.

12. «Proposiciones de Boabdil para la entrega de Granada», en M. GARRIDO ATIENZA, Las capitulaciones para la entrega de Granada, ed. facsímil, Granada, Universidad de Granada, 1992, p. 231 (en adelante Proposiciones).

13. “Capitulaciones para la entrega de Granada", 25 de noviembre 1491: AGS, Patronato Real, leg. 11, fol. 207, en M.A. LADERO QUESADA, Granada..., apéndice documental n. 50, p. 437 (en adelante: Capitulaciones). 
dad musulmana. Sin embargo, mientras Boabdil había pedido que los litigios entre musulmanes y cristianos fuesen juzgados por el cadí (como lo eran bajo los gobiernos islámicos), los Reyes estipularon que estos casos tenían que ser resueltos en presencia de un juez cristiano y de un juez musulmán, para evitar las reclamaciones ${ }^{14}$. No vamos a profundizar este tema, ya que proponemos llamar la atención sobre una reformulación de las peticiones de Boabdil que nos parece muy significativa del trabajo realizado por los redactores del texto.

Se trata de las modalidades de la llamada a salat, la oración musulmana. En los países islámicos, la voz del almuédano, subido en el minarete de la mezquita, llamaba los fieles a la oración cinco veces al día ${ }^{15}$. El texto de Boabdil menciona expresamente la voz del almuédano ("dar vozes"), pretendiendo así mantener una tradición cuyo origen se atribuye al mismo Profeta Mahoma. La cláusula otorgada por los Reyes Católicos cambia del todo el ambiente sonoro de la cuidad. Las torres de las mezquitas quedan en pie y se menciona la llamada a la salat, pero sin la expresión "dar voces". Esta modificación no parece fortuita. En adelante, no se consiente oír las voces de los almuédanos granadinos.

En la época de la Reconquista, por ejemplo en el reino de Valencia conquistado en el siglo XIII, ya se había planteado la cuestión de la llamada a la salat por el canto de los almuédanos. El texto del anuncio de la salat proclama que "No hay ningún Dios sino Allah" y "Muhammad es el enviado de Allah". Para las autoridades cristianas, eran proclamaciones de índole blasfematoria, hasta tal punto que en 1312, bajo el papa Clemente V, el concilio de Vienne en Francia había prohibido tajantemente la llamada vocal a la salat para los musulmanes que vivían en los países cristianos, y había confiado a los príncipes el deber de hacer respetar esta interdicción:

"Para la ofensa del nombre divino y el oprobio de la fe cristiana, sucede que en ciertas regiones del mundo sujetas a príncipes cristianos, donde sarracenos moran con cristianos, ora a parte, ora mezclados con ellos, sus sacerdotes, vulgarmente llamados Zabazala, invocan y anuncian en voz alta el nombre de Mahoma en sus templos o mezquitas, donde los sarracenos se reúnen para adorar el pérfido Mahoma, y eso cada día a ciertas horas, en un puesto elevado, y que profesan públicamente ciertas palabras en su honor, lo cual oyen cristianos y sarracenos [...].

Como estas prácticas que desagradan a la majestad divina no se deben tolerar más, con la aprobación del santo concilio, prohibimos con el máximo rigor que se produzcan en los territorios de los cristianos. Ordenamos con la mayor potencia e invocando el juicio divino, a todos y a cada uno de los príncipes cristianos bajo el dominio de los cuales los sarracenos moran y estas cosas se producen, eliminar totalmente de sus territorios y procurar que se elimine el oprobio que esto conlleva para con ellos mismos y con los otros fieles cristianos, pensando como lo deben

14. Ver A. Galán SÁnchez, Los Mudéjares del Reino de Granada, Granada, Universidad de Granada, 1991, pp. 154-156.

15. «Adhan», Encyclopédie de l'islam, t. I, Paris-Leiden, Brill-Editions Maisonneuve \& Larose, 1991, pp. 193-194. 
a la recompensa de la beatitud eterna que recibirán. Prohibimos expresamente que cualquier dependiendo de su autoridad se atreve, o esté animado a invocar o profesar públicamente, como esta dicho, el nombre sacrilegio de Mahoma"16.

Este texto pertenece a un conjunto de disposiciones adoptadas por el concilio para la reforma de la Iglesia y del clero. Entre estas disposiciones, sigue inmediatamente al decreto Inter sollicitudines que ordena la creación de cátedras de hebreo, árabe y caldeo en las universidades de París, Oxford, Bolonia y Salamanca. Al principio del siglo XIV, el desmoronamiento de la presencia de los Latinos en Tierra Santa y la condenación de los Templarios no impedían al papa Clemente $\mathrm{V}$ manifestar su voluntad de contener, o de reducir, la presencia del Islam tanto en Occidente como en Oriente, por la predicación, las leyes o las armas. En esta perspectiva, el enviado del rey de Aragón Jaime II al concilio de Vienne aconsejó lanzar un ataque contra el reino de Granada. Si las expediciones militares quedaron en estado de proyecto, la prohibición del canto de los almuédanos fue la traducción concreta del rechazo de la presencia islámica en la Cristiandad. La decisión del concilio de Vienne fue inserta rápidamente en las Clementinas, compilación del derecho canónico que completaba el Decreto de Graciano y las Decretales de Gregorio IX; fue conocida en adelante por los juristas como el canon Cedit ${ }^{17}$.

Fuera de España, donde no había frontera con países islámicos, los canonistas no tenían la oportunidad de conocer las prácticas musulmanas y no podían entender perfectamente los motivos de esta disposición. La glosa del texto, redactada por Johannes Andreae algunos años después del concilio de Vienne, se encarga de darles las informaciones necesarias. Así, un etnólogo, Johannes Andreae, profesor en Bolonia y famoso canonista, recogió sus datos dirigiéndose a un cierto señor Jean, tesorero del rey de Francia, que había permanecido en tierra islámica durante cuarenta años en cautividad. Johannes Andreae presenta en primer lugar los "foquis" (alfaquíes), una categoría de sacerdotes que se diferencia de los "alhages" (hadj), los cuales han hecho la peregrinación a La Meca. En segundo lugar describe la función de los almuédanos:

"Cada mezquita tiene un sacerdote de los primeros, y un ministro que llaman muetdem, quien llama a la oración, supliendo la falta de campanario, porque, aunque los sarracenos los aprecian mucho, como los cristianos les precedieron en este uso no los quieren tener.

El oficio de la llamada a la oración es como se sigue: á ciertas horas que precisaremos después, sube en la torre cuadrada de la mezquita, provista de una amplia ventana, y desde allí grita, en voz alta y tapándose los oídos con los dedos para que su voz se oiga más fuerte, unas palabras en su idioma que significan: 'No hay otro Dios, sino Dios, y Mahoma su enviado, venid hacer la ora-

16. "Cedit", texto latino en G. Alberigo et al., Les conciles œecuméniques. Les décrets, t. II-1, Paris, Cerf, 1994, p. 786.

17. Clementinas, tit. "De Iudaeis et Sarracenis", cap. único. 
ción en descubriendo vuestros corazones'. Y luego añade: 'legalil ille halla', lo cual quiere decir: 'No hay otro vencedor sino Dios'. Todos los soldados musulmanes llevan estas palabras en sus escudos. Y añade: 'Dios es omnipotente" ${ }^{\prime 18}$.

Al principio del siglo XV, el cardenal de Florencia Francisco Zabarella utilizó estas informaciones en su comentario de las Clementinas, el cual conservó una fuerte popularidad entre los canonistas hasta el final del siglo XVI. Con lo cual nos acercamos a las capitulaciones de Granada, porque el cardenal expresa su opinión sobre el papel de los príncipes cristianos que tienen vasallos musulmanes. El deber de estos príncipes es que se cumpla la prohibición de la invocación pública del nombre de Mahoma; la Iglesia no puede hacerse cargo del asunto porque los musulmanes, no siendo bautizados, no se encuentran bajo su jurisdicción. Los príncipes cristianos deben también impedir todo lo que podría perjudicar a la fe en sus territorios respectivos. Este deber parece ir más allá de la cuestión de los almuecines, ya que el cardenal menciona un debate entre canonistas para saber si la prohibición de la invocación de Mahoma es vigente incluso en el marco privado. Algunos juristas, que consideraban como ilegal cualquier práctica del Islam, tanto privada como pública, rechazaban la libertad de culto concedida a los musulmanes en los países cristianos, aun con las restricciones establecidas por el derecho canónico ${ }^{19}$.

La doctrina común en esta materia era que los musulmanes, mientras no se sujetaban a la jurisdicción de la Iglesia por la recepción del bautismo, conservaban su autonomía en el marco privado y debían adaptar las manifestaciones exteriores de su culto con arreglo a unas legislaciones civiles más o menos estrictas. A partir de 1318, el rey de Aragón Jaime II aplicó la prohibición decretada por el concilio de Vienne, castigando a los infractores con la pena de muerte. Sin embargo, los musulmanes del reino de Valencia obtuvieron derogaciones locales como en Játiva en 1357, y muchos señores autorizaron la llamada a la salat para no desagradar a sus vasallos, como también lo hizo el rey Pedro el Ceremonioso entre 1366 y 1370 en varios lugares para estimular la repoblación del territorio. Las Cortes de Valencia de 1403, bajo el rey Martín el Humano, prohibieron que en el reino sea "cridat ab veu d'hom en torres, mezquites o altres locs publicament

18. "Et quelibet mesquita habet unum sacerdotem de primis, et unum ministrum qui vocant Muetdem, quod sonat preco, qui supplet defectum campanarium, quas licet Sarraceni multum commendent, quia tunc Christiani in eis habendis prevenerunt, nolunt eis uti. Illius preconis officium est: quia horis, de quibus infra dicetur, ascendit turrim mesquite quadratam qualibet, et parte sui fenestram magnam habentem, et ad illarum quamlibet clamat alta voce obturatis auribus cum digitis ut vox fortius resonet, in sua lingua verba haec sonantiam. Nihil aliud posse, nisi Deus, et Machometus eius nuncius, venite ad orationem faciendam in revelationem pectorum vestrorum. Et postea submittit, legalil ille halla, quod est dicere, non est aliud victor nisi Deus. Et haec verba omnes milites Sarraceni portant in scutis suis. Et adhuc submittit, Deus est omnipotens", Clementis quinti constituciones, quas Clementinas vocant... cum summariis, casibus notabilibus, iuris patronatus arborae, ac additionibus tam ex Ioannis Imolae quam Petri Ancharani, Zabarellae, Barbatiae, Panormitani... Lugduni, 1541, p. 57 v.

19. F. ZABARElla, In Clementinarum volumen commentaria, Venetiis, 1602, p. 169. 
lo infiel e reprovat nom de Mahomet" ${ }^{20}$. A falta de la voz, los almuecines tuvieron que usar varios instrumentos para llamar a la oración, como tambores, cuernos o añafiles -unas largas trompetas utilizadas en los campos de batalla para llamar a los soldados-. En la ciudad de Valencia, bajo el reinado de Fernando, se prohibía incluso llamar sonando un cuerno ${ }^{21}$. La prohibición de la llamada vocal a la salat planteaba a los musulmanes una dificultad no solamente práctica, sino también política, ya que simbolizaba una situación de inferioridad en cuanto a los cristianos: entre los doctores, se discutía para decidir si era un motivo de emigración de los mudéjares hacia los países islámicos ${ }^{22}$.

Se debe pensar que la modificación del texto de Boabdil, en tal contexto, tendía a prohibir el canto de los almuecines. De hecho, en la Granada cristiana, el nombre de Mahoma dejó de gritarse desde los minaretes y el toque de los añafiles se substituyó a la voz humana para señalar a los fieles las horas de la salat. Lo señala un testigo musulmán anónimo, lamentando las vejaciones infligidas por los cristianos después de los primeros años de convivencia: "hasta se suspendió el pregón del almuédano en las torres" ${ }^{23}$. Cuando, en diciembre de 1499, la intervención enérgica del cardenal Cisneros llegó a conseguir la conversión de las élites musulmanas y la parálisis del culto, los almuédanos depusieron sus instrumentos de trabajo. El cardenal pudo anunciar el hecho al cabildo de Toledo, y enviarle los preciosos añafiles como símbolos del triunfo de la fe cristiana sobre la infidelidad:

"Entre muchos alfaquies de las mas principales personas de todo este reyno que se han convertido se han tornado cristianos dos almuédanos que llamavan a los moros a su oración, o maldición, y nos han traydo los añafiles con que tañían, las quales mandamos guardar para que se pongan en esa nuestra iglesia en algun lugar. Desde el dia de Nuestra Senora aca no han llamado ni se ha oydo cosa del mundo en la mezquita mayor de Albaicín, e en avernos traydo las trompetas et añafiles con que llamavan a la zala y ser convertidos los que llamavan, recebimos aquellos añafiles como si nos entregaran las llaves, e sera bien que pongan aquellos añafiles, que son muy grandes, de azofar, en el altar de Sant Alifonso"24.

20. M.T. FERRER MALLOL, «Frontera, convivencia y proselitismo entre cristianos y moros en los textos de Francesc Eiximenis y de San Vicente Ferrer», en J.M. Sото RÁbanos (ed.), Pensamiento medieval hispano. Homenaje a Horacio Santiago Otero, Madrid, C.S.I.C., 1998, pp. 1588-1590; J. HINOjOsa Montalvo, Los mudéjares. La voz del Islam en la España cristiana, Teruel, Centro de Estudios Mudéjares, 2002, pp. 122-125.

21. M.D. MEYERSON, The Muslims of Valencia in the age of Fernando and Isabel. Between coexistence and Crusade, Berkeley, University of California Press, 1991, p. 43.

22. P.S. VAN KONINGSVELD y G.A. WiEgers, op. cit., pp. 25-26.

23. A. Bustani (ed.), Fragmento de la época sobre noticias de los reyes Nazaritas o capitulación de Granada y emigración de los andaluces a Marruecos. Lo presenta, texto árabe con prólogo, notas, comentarios e índices, Alfredo Bustani. La versión española ha sido hecha por D. Carlos Quirós, Larache, Artes graficas bosca, 1940, p. 51.

24. Carta del arzobispo Francisco Jiménez de Cisneros al deán y al cabildo de la catedral de Toledo, 23 de diciembre de 1499, Madrid, BN, Ms. 13020, fol. 95, en M.A. LADERO QuESADA, Granada..., apéndice documental n. 85, pp. 491-492. 


\section{SEÑALES DE IDENTIFICACIÓN}

Con la libertad de practicar su religión, los musulmanes de Granada obtuvieron también un permiso importante:

"Item es asentado que agora nin en tiempo alguno sus Altezas nin el dicho Señor Principe, ni sus descendientes, no hayan de apremiar ni apremien á los dichos moros, así á los que hoy son vivos como los que dellos subcedieren, á que traigan señales" 25 .

Esta cláusula de las capitulaciones repite, e incluso acentúa, el texto propuesto por Boabdil:

“Otrosy, que sus altezas y sus descendientes non mandarán poner señales á los moros, agora ni en ningund tiempo para siempre jamás"26.

Los musulmanes de Granada no tenían la obligación de señalar su pertenencia a la comunidad islámica con una señal exterior. Para ellos se trataba de una cuestión de dignidad. En los países islámicos se imponía a los dhimmis judíos y cristianos diferenciarse de los musulmanes por alguna particularidad en el vestido, variable según las regiones y las épocas: zunnar o cintura en el Egipto del siglo XVI, color de las babuchas en el imperio otomano, en el siglo XVII ${ }^{27}$. En la Granada musulmana, los hombres judíos se identificaban con una pieza de tejido amarillo, y las mujeres con una campanita ${ }^{28}$. Exentos de tal obligación por las capitulaciones, los vencidos de Granada evitaban una señal de inferioridad y de humillación.

¿Por qué accedieron los Reyes Católicos a esta petición de Boabdil? Pues al final de la Edad Media se tendía generalmente, en los países cristianos, a establecer una serie de discriminaciones entre las minorías religiosas y la mayoría de la población por medio de señales exteriores o de barrios separados. En 1215, bajo el papa Inocencio III, el IV concilio de Laterano, en su decreto 68, había decidido que los hombres y mujeres, judíos y sarracenos, debían "diferenciarse públicamente de la otra gente por la cualidad de su vestido, en toda provincia cristiana y en todo tiempo". Era necesario evitar toda promiscuidad sexual y todo trato familiar entre los cristianos y los infieles, en aquella época de severidad dogmática de la Iglesia. Esta disposición, consignada en las Decretales, fue integrada en el derecho canónico, formando el canon Nonnullis $^{29}$. Se aplicó por ejemplo en la cuidad pontificia de Aviñón, donde los hombres judíos

25. Capitulaciones, p. 438.

26. Proposiciones, p. 232.

27. J. SCHACHT, Introduction au droit musulman, Paris, Maisonneuve et Larose, 1983, p. 111; B. LEWIS, Juifs en terre d'Islam, Paris, Flammarion, 1986, p. 161.

28. R. ARIÉ, L'Espagne musulmane au temps des Nasrides (1232-1492), Paris, De Boccard, 1990, 2 ${ }^{\mathrm{a}}$ ed., p. 331.

29. "In nonnullis provinciis a Christianis Iudaeos seu Sarracenos habitus distinguit diversitas, sed in quibusdam sic quaedam inolevit confusio, ut nulla differentia discernantur. Unde contingit 
tenían que llevar la rouelle, una pieza en forma de rueda cosida en el vestido, en el lado izquierdo del pecho ${ }^{30}$. En Castilla y en Aragón, a partir del siglo XIII, se establecieron normas siempre más precisas para diferenciar los mudéjares de los cristianos, lo cual indica que no se identificaban a primera vista. Se prohibió a los musulmanes utilizar adornos y tejidos específicos, festivos y lujosos, y se les impuso peinados o cortes de cabellos y de barba variables según las modas. En 1408, Enrique II de Castilla dispuso que llevaran una luneta azul sobre el hombro derecho, y los varones un capuz de color amarillo-verdoso. En adelante, la luna azul se conservó como señal distintiva de los musulmanes, pero no parece que esta norma se observara estrictamente, ya que las Cortes de Toledo de 1480 insistieron sobre su seguimiento ${ }^{31}$.

En las capitulaciones de Granada, la exención de señales distintivas deroga el derecho real de Castilla, y va contra el derecho canónico. Es cierto que en esta ciudad una multitud de usos en el vestido, en la alimentación y en el modo de vida, así como el idioma, señalaban la diferencia entre los musulmanes y los cristianos. Los musulmanes de Granada hablaban el árabe y llevaban nombres islámicos, entre los cuales los más comunes eran Mohammad, Ahmed y Ali para los hombres, Aïcha, Fátima y Mariem para las mujeres ${ }^{32}$. Hacia 1499, en los años de la conversión masiva al Cristianismo, el arzobispo Hernando de Talavera insistía en las profundas modificaciones en el modo de vida que debían acompañar al bautismo:

"Mas para que vuestra conversación sea syn escandalo a los cristianos de nación y non piensen que aun teneys la seta de Mahomad en el coraçon es menester que vos conformeys en todo y por todo a la buena y honesta conversación de los buenos y honestos cristianos y cristianas en vestir y calçar y afeytar, y en comer y en mesas y viandas guisadas como comúnmente las guisan, y en vuestro andar y en vuestro dar y tomar y mucho y mas que mucho en vuestro hablar, olvidando quanto pudieredes la lengua arabiga y faziéndola olvidar y que nunca se hable en vuestras casas" ${ }^{\prime 3}$.

Es probable que, en 1491, no pareciera necesario a los Reyes establecer otras señales discriminatorias. Las huellas de la cultura islámica estaban bastante vi-

interdum, quod per errorem Christiani, Iudaeorum seu Sarracenorum, et Iudaei seu Sarraceni Christianorum mulieribus commisceantur. Ne igitur tam damnatae commixionis excessus per velamentum huiusmodi ulterioris excusationis ulterius possint habere diffugium, statuimus, ut tales utriusque sexus in omni christianorum provincia et omni tempore, qualitate habitus publice ab aliis populis distinguantur". Decretales de Gregorio IX, 5.6.15.

30. R. Moulinas, Les juifs du pape. Avignon et le Comtat Venaissin, Paris, Albin Michel, 1992, p. 22.

31. J. Hinojosa Montalvo, op. cit., pp. 293-298.

32. M.A. LADERO QUESADA, «Los bautismos...», pp. 494-542. Sobre la sociedad granadina al momento de la conversión, A. CARRASCO GARCÍA, «Huellas de la sociedad musulmana granadina: la conversión del Albayzín (1499-1500)», En la España medieval, 30, 2007, pp. 335-380.

33. Hernando de TALAVERA, «Instrucción y carta para los vecinos del Albayçin», "en que les amonesta lo que deben hazer", Div. Castilla, L. 8, fol. 114, en M.A. LADERO QUESADA, Granada..., pp. 545-547, doc. 127. 
sibles como para diferenciar a los musulmanes en Granada, lo que no era el caso en regiones de Castilla donde los mudéjares, en posición de minoría desde siglos, habían adoptado el vestido y el idioma de los cristianos. La imposición de señales distintivas sólo se entiende en la coexistencia de dos grupos religiosos que se pretende conservar separados. La exención otorgada en las capitulaciones indica que, al final de la guerra de Granada, los Reyes Católicos ya se situaban en la perspectiva de la conversión de los musulmanes, a corto o mediano plazo. Hubiera sido absurdo imponer señales vejatorias a una población que estaba destinada a adoptar tanto la religión como los usos y costumbres de los cristianos.

\section{¿UNA GARANTÍA REAL CONTRA LAS CONVERSIONES FORZADAS?}

Entre las libertades religiosas de los vencidos consignadas en las capitulaciones aparece una fórmula muy general de garantía contra las conversiones forzadas:

"Item es asentado e concordado que á ningund moro ni mora non fagan fuerza á que se torne cristiano nin cristiana" ${ }^{34}$.

En razón de esta cláusula y de las otras dos sobre los convertidos que estudiaremos a continuación, los Reyes Católicos fueron tachados de no haber respetado las capitulaciones después que el cardenal Cisneros puso en marcha, en el otoño de 1499, una política muy voluntarista de conversión de los granadinos al Cristianismo. Esto nos incita a detenernos sobre la noción de conversión forzada.

Notamos, en primer lugar, que esta cláusula es un caso particular, ya que no corresponde a ninguna petición del rey Boabdil. Sin embargo, su inserción en las capitulaciones de Granada no es innovadora, sino que sigue el derecho real castellano, y en particular esta ley de las Siete Partidas de Alfonso X el Sabio (1252-1284):

"Como los cristianos por buenas palabras y no por premia deven convertir los moros. Por buenas palabras convenibles y otrosi predicaciones [deven trabajar los cristianos] de convertir a los moros para fazerles creer la nuestra fe y aduzirlos a ella y non por fuerça ni por premia. Ca si voluntad de nuestro Señor fuese delos aduzir a ella y de gela fazer creer el por fuerça apremiaria si quisiesse que ha acabado poderio de lo fazer mas el non se paga de servicio que fazen los ombres a miedo, mas de aquel que se faze de grado y sin premia ninguna y pues el no los quiere apremiar ni fazer fuerça, por esto defendemos que ninguno non los apremie ni les faga fuerça sobre esta razon" ${ }^{\prime 35}$.

La ley de las Partidas ofrece una clave de interpretación de la cláusula de 1491. En las Partidas, la prohibición de las conversiones forzadas se encuentra

34. Capitulaciones, p. 442.

35. Las Siete Partidas de Alfonso X el Sabio, Sevilla, 1491, Partida VII, título XXV, ley II. 
íntimamente ligada con el proyecto de conversión de los musulmanes al Cristianismo. Queda claro que la norma establecida por la ley se refiere solamente a los medios empleados para conseguir este objetivo considerado como sumamente positivo.

En Granada también resalta la perfecta compatibilidad entre la prohibición de las conversiones forzadas y la dinámica de la conversión de los vencidos. En diciembre de 1491, los Reyes querían poner fin a la guerra con la conquista de la ciudad, sin tardanza. El arte de redactar las capitulaciones consistió en dar satisfacción a las peticiones de Boabdil, reservando, mientras tanto, unas vías de acción para la conversión de la población musulmana. Podemos suponer que esta cláusula pretendía tranquilizar a los vencidos y facilitarles el paso bajo el dominio de soberanos cristianos. No se precisa lo que se entiende por la expresión "fazer fuerza". La misma imprecisión caracteriza las declaraciones del humanista Pedro Mártir de Anglería, enviado en 1502 al sultán mameluco Qansuh Al-Ghuri para desmentir las acusaciones proferidas contra los Reyes Católicos:

“El Rey y la Reina católicos de España, a quienes represento, declaran ser cristianos mucho más por sus hechos que de nombre. Llamamos nosotros cristianos a los que se esfuerzan por seguir las huellas de Cristo, profesan su doctrina y guardan su ley. Cristo jamás forzó a nadie a que, contra su voluntad, le siguiera para ganárselo para sí; nunca mando que se emplease la fuerza a fin de hacer a uno cristiano; al contrario, nuestra religión ordena abiertamente que nadie se atreva a incitar por la violencia o el miedo a que profesa una religión distinta" ${ }^{36}$.

El derecho canónico permite definir la noción de conversión forzada, hasta tal punto que llegaremos a relativizar la autoridad del derecho real en esta materia. En efecto, las palabras del enviado de los Reyes simplifican una doctrina canónica que, en cuanto al uso de la fuerza para obtener conversiones, no era tan categórica. Al final del siglo XV, esta doctrina llevaba varios siglos de maduración, habiéndose elaborado mayormente en las relaciones con los judíos. Una serie de textos juzgaron un papel decisivo en este proceso.

Uno de los textos principales que fundaban la protección de aquellos en la Europa medieval era el canon Qui sincera del Decreto de Graciano. Sacado de una carta dirigida en 602 al obispo de Nápoles por Gregorio Magno para con-

36. "Catholici rex et regina hispaniarum (quos reffero) se multo magis re quam nomine christianos esse profitentur: christianum eum nos apellamus qui christi vestigia nititur imitari doctrinam sequi legem servare: christus neminem unquam ad se invitum adducere aut allicere est conatus. Vim cuiquam ut christianus efficiatur inferri praecepit nunquam: immo nostra lege cautus est aperte ne quisquam audeat alienae legis ullius cultorem metu aut vi impellere", P. Martyris Angli Mediolanensis Apostolici Regii consiliarii Legatio Babylonica, en L. GARCíA y GARCÍA, Una embajada de los Reyes Católicos a Egipto, Madrid, Consejo Superior de Investigaciones Científicas, 1947, pp. 153 [latin]-158 [trad. cast.]. Sobre este episodio, J.E. LÓPEZ DE COCA CASTAÑER, «Mamelucos, otomanos y caída del reino de Granada», En la España medieval, 28, 2005, pp. 229-258. 
testar a las quejas de los judíos de la cuidad contra los atentados a sus derechos, el canon afirma, en su preámbulo, que los medios empleados para atraer a los paganos hacia la fe cristiana deben ser blandos, y no recios ${ }^{37}$. Se empleó contra las conversiones forzadas. Sin embargo, los canonistas no tardaron en matizar su contenido, sustituyendo a la expresión original "medios blandos, y no medios recios" ["blandimentis... non asperitatibus"] otra más permisiva en cuanto a los medios empleados para convertir a los infieles: "medios blandos, antes que recios" ["blandimentis, potius quam asperitatibus"]. Esta lectura del canon Qui sincera se presenta, por ejemplo, en dos Sumas de gran influencia hasta el siglo XVI, la de Ramón de Peñafort y la de Goffredus de Trani ${ }^{38}$.

Un segundo texto alegado con frecuencia contra las conversiones forzadas era el canon De Iudeis del Decreto, sacado del IV concilio de Toledo reunido en 633 bajo la presidencia de Isidoro, obispo de Sevilla. Este concilio tenía que enfrentar las consecuencias de las persecuciones llevadas contra los judíos por el rey Sisebuto a partir de 616. En cuanto a los judíos que se habían exiliado para huir de la persecución y habían vuelto a España durante el reinado de Suintila, el concilio afirma que la recepción de la fe cristiana procede de la propia responsabilidad del individuo, y no debe imponerse por medios violentos: "En cuanto a los judíos, el santo sínodo prescribe que nadie les lleve a la fe por fuerza"39. La alusión al pecado original y al endurecimiento de los judíos muestra que la prohibición de la conversión forzada se funda en una concepción teológica de la salvación y no, por supuesto, sobre sentimientos de humanidad hacia los infieles. A continuación, el concilio resolvió el problema planteado por los judíos que, habiendo recibido el bautismo durante las persecuciones del "muy piadoso príncipe Sisebuto", habían vuelto a la ley mosaica:

"Conviene forzarlos a observar la fe que han recibido por fuerza o por necesidad, para que no sea blasfemado el nombre del Señor, y que la fe que recibieron no sea tenida por ruin y despreciable" ${ }^{\prime 4}$.

Con esta conclusión, el canon De Iudeis llegaba a asociar la prohibición de las conversiones forzadas con el pleno reconocimiento de los efectos de aquellas: la integración de los infieles al cuerpo de Cristo por el bautismo era un hecho irreversible.

37. "Qui sincera intentione extraneos a Christiana religione ad fidem cupiunt rectam adducere, blandimentis debent, non asperitatibus studere [...]", Decretum Gratiani, D.45 c.3.

38. Sobre esta evolución, B.Z. KeDAR, Crusade and mission: European approaches toward the Muslims, Princeton, Princeton University Press, 1984, pp. 73-74.

39. "De Iudeis autem precepit sancta sinodus, nemini deinceps uim ad credendum inferre.[...]", Decretum Graciani, D.45, c.5; G. MARTínez DíEz y F. RodríGUEZ, La colección canónica hispana, t. V, Concilios Hispanos, Parte 2, Madrid, C.S.I.C., 1992, p. 235.

40. “Oportet, ut fidem, quam ui uel necessitate susceperint, tenere cogantur, ne nomen Domini blasphemetur, et fides, quam susceperunt, uilis ac contemptibilis, habeatur", ibídem, p. 236. 
Inserto en el Decreto, este texto fue empleado en el canon Maiores de las Decretales, que es la tercera autoridad habitualmente alegada en este tema ${ }^{41}$. El canon Maiores tiene su origen en una carta del papa Inocencio III, escrita en 1201 para contestar a una pregunta del obispo de Arles sobre la validez del sacramento del bautismo cuando se confería a los niños, punto rechazado, a la sazón, por los herejes. En su respuesta, el papa extendió su reflexión mucho mas allá de la pregunta inicial, resolviendo el problema de la validez del bautismo en varias circunstancias ${ }^{42}$. Habiendo mostrado la necesidad de bautizar a los niños, Inocencio III abordó luego el caso de los adultos que no dan su consentimiento a la recepción del sacramento, entre los cuales los que lo reciben por fuerza. La intención del papa era de determinar la doctrina, interviniendo en el debate sobre el bautismo forzado y sus efectos que, en estos años, dividía a los doctores de Bolonia. Algunos opinaban que el bautismo era válido incluso cuando se confería por fuerza. En contra de los más radicales, el papa enunció la condenación siguiente:

"Por cierto, es contrario a la religión cristiana que sea forzado a recibirla y a observarla un individuo que expresa siempre su oposición y su rechazo" ${ }^{\prime 4}$.

A continuación, Inocencio III utilizó y simplificó la distinción entre varios tipos de fuerza, distinción elaborada por Rufin, un eminente canonista de Bolonia que terminó su comentario del Decreto hacia $1164^{44}$. La fuerza "absoluta" o "precisa" es la que se emplea contra un individuo que expresa su oposición entera y constante a la recepción del bautismo: Inocencio III afirmó su carácter ilícito y su incapacidad a producir un bautismo válido. Al contrario, la fuerza "condicional" consiste en emplear medios violentos para obtener el consentimiento del individuo. Inocencio III ratificó la distinción entre fuerza absoluta y fuera condicional y, sin pronunciarse sobre la licitud de la segunda, afirmó su capacidad a producir bautismos plenamente válidos, así como la necesidad de obligar a los individuos bautizados en tales circunstancias a "observar la fe cristiana". La amenaza de muerte se incluye en la categoría de la fuerza condicional: la imagen del cuchillo en la garganta, empleada por Rufin, es aún

41. Sobre el empleo de estos textos para afirmar la validez de los bautismos de musulmanes conferidos durante la Germanía de Valencia, nos permitimos remitir a nuestro trabajo: «La conversion des musulmans de Valence (1521-1525) et la doctrine de l'Eglise sur les baptêmes forcés», Revue Historique, 648, 2008, pp. 819-855.

42. C. EGGER, «Papst Innocenz III als Theologe», Archivum Historiae Pontificiae, 1992, 30, pp. 5-123; Ch. de MIRAMON, «Innocent III, Huguccio de Ferrare e Hubert de Pirovano. Droit canonique, théologie et philosophie dans les années 1180», en W.P. MüLLER y M.E. SOMMAR (eds.), Medieval Fondations of the Western Legal Tradition. A Tribute to Kenneth Pennington, Washington, 2006, pp. 320-346.

43. "Verum id est religioni Christianae contrarium, ut semper invitus et penitus contradicens ad recipiendam et servandam Christianitatem aliquis compellatur", Decretales de Gregorio IX, 3.42.3.

44. Rufin, Summa Decretorum (1164), ad C. 22 q. 5 en Die «Summa Decretorum» des Magister Rufinus, herausgegeben von Dr. Heinrich Singer, Paderborn, F. Schöningh, 1902, p. 400. 
más elocuente que la evocación de "los terrores y los suplicios" ["terroribus atque suppliciis"] en la carta de Inocencio III, el cual concluye citando la conclusión del canon De Iudeis.

En la reflexión posterior de los canonistas y de los teólogos sobre la validez del bautismo y la conversión forzada, el canon De Iudeis del Decreto y el canon Maiores de las Decretales son autoridades omnipresentes. En consecuencia, la condenación del uso de la fuerza para llevar a los infieles a la fe cristiana quedó estrechamente asociada con la legitimación de tal uso para obligar a aquellos que, después del bautismo, habían vuelto a caer en sus prácticas anteriores -pasando, entonces, del estatuto de infieles al de herejes- a cumplir lo que habían prometido cuando habían recibido este sacramento ${ }^{45}$.

Además, la validación en el derecho canónico de los bautismos conferidos en circunstancias de fuerza condicional (en la práctica, bajo la amenaza de muerte), impidió en adelante todo recurso contra las conversiones forzadas, como se vio inmediatamente después de los numerosos ataques perpetrados contra las juderías en Castilla y en Aragón en el verano de 1391. Cuando, en el "avalot dels juheus" del 9 de julio de 1391, los habitantes de la judería de Valencia perecieron o tuvieron que recibir el bautismo, el rey de Aragón Juan I no pudo hacer más que cualificar de "detestable crimen" estos acontecimientos, antes de confiscar para el Tesoro Real los despojos de las aljamas ${ }^{46}$.

Así, la cláusula de las capitulaciones de Granada contra las conversiones forzadas, inserta por iniciativa de los Reyes Católicos, puede interpretarse como una prueba del respeto de los soberanos hacia la ley cristiana: su intención expresa era conformarse con la doctrina canónica común que iba contra tales conversiones. Bien es verdad que una opinión minoritaria fundada en los cánones De Iudeis y Maiores, la del franciscano Juan Duns Scot al principio del siglo XIV, relevada por el profesor de Tubingen Gabriel Biel al final del siglo XV, llegaba a aconsejar a los príncipes cristianos hacer uso de la fuerza "con amenazas y terrores" para llevar al bautismo a los infieles que vivían en sus dominios, tomando ejemplo en el piadoso rey Sisebuto ${ }^{47}$. La cláusula de 1491 manifiesta que los Reyes no pretendían seguir la línea de la persecución violenta de la minoría musulmana. Pero no estaba en sus manos anular los efectos de unas conversiones que pudieran efectuarse por iniciativa ajena, in-

45. Un ejemplo de tal asociación es la respuesta de santo Tomás a la pregunta "¿Débense forzar los infieles a la fe?" en la Suma Theologica, Tomás de AQuino [Thomas d'Aquin], Somme théologique, $\mathrm{II}^{\mathrm{a}} \mathrm{II}^{\mathrm{ae}}$, q. 10, art. 8, Editions de la Revue des jeunes, vol. 27-28, Paris Desclée \& Cie, 1950, pp. 101-104.

46. Y.F. BAER, Historia de los judios en la España cristiana, Barcelona, Riopiedras, 1998, pp. 531-545.

47. I. Duns Scotus, Ordinatio, L. 4, en Opera Omnia, editio minor III/2 Opera theologica (a cura di Giovanni Lauriola), Bari, Editrice Alberobello, 2001, pp. 529-530; G. BIEL, Gabrielis Biel collectorium circa quattuor libros Sententiarum, 4, 1, Libri quarti pars prima: dist. 1-14, Tübingen, J.C.B. Mohr-P. Siebeck, 1975, p. 203. 
cluso empleando medios violentos para obtener el consentimiento de los musulmanes. Además, las autoridades cristianas podían, lícitamente, buscar la conversión de los musulmanes por "medios blandos" como la predicación, los favores $\mathrm{u}$ otros medios de persuasión; y no se les obligaba a excluir del todo, para completar a los "medios blandos", el empleo de "medios recios", siempre que dejaran a los infieles la posibilidad de consentir al bautismo para evitar otros tratamientos. Sobre todo, esta garantía (más bien tenue, nos parece) contra el uso de la fuerza solo se otorgaba a los "moros y moras". Veamos ahora lo que se entendía por esta designación.

\section{LOS CRISTIANOS CONVERTIDOS AL ISLAM}

Separados, antes de la conquista del reino nasri, por una frontera que los guerreros, los comerciantes y los cautivos pasaban con tanta frecuencia, castellanos y granadinos tuvieron que tratar un problema de los más delicados, el de los tránsfugas de una u otra religión ${ }^{48}$. El Islam y el Cristianismo prohibían la apostasía y la castigaban con penas máximas. La entrada en el grupo de los fieles era irreversible tanto si se hacía por transmisión familiar como por conversión. Además, los musulmanes como los cristianos se esforzaban, desde siglos, en aumentar el número de sus correligionarios por varios medios, pacíficos o coercitivos. La población de Granada, en 1492, era el reflejo de esta realidad. Los musulmanes, en su mayoría, eran los descendientes de los habitantes cristianos o judíos de la antigua Hispania y no se diferenciaban radicalmente, en cuanto a los caracteres biológicos, de los conquistadores castellanos, aunque muchos quedaban convencidos de sus orígenes árabes -los descendientes de conversos, ya integrados en la sociedad musulmana, se habían dotado de genealogías forjadas, consideradas como auténticas en las generaciones posteriores $^{49}$-. Por otra parte, las expediciones militares conducidas al otro lado de la frontera habían llevado a Granada a millares de hombres y mujeres cristianos, luego reducidos a la esclavitud y empleados en todos los sectores económicos de la ciudad. Entre ellos, algunos se habían convertido al Islam, a menudo para mejorar su condición y conservar la libertad, ya que el Islam prohibía esclavizar a los musulmanes. Además, Granada contaba con individuos que, marginados en la sociedad cristiana, habían pasado la frontera en busca de la impunidad y de una vida más prospera, y se habían adherido al Islam para favorecer su integración. Los castellanos designaban a todos estos convertidos por el nombre de elches, considerándolos como renegados y apóstatas.

48. M. GONZÁLEZ JiMÉNEZ, «La frontera entre Andalucía y Granada: realidades bélicas, socio-económicas y culturales», en M.A. LADERO QUESADA (dir.), La incorporación..., pp. 87-145.

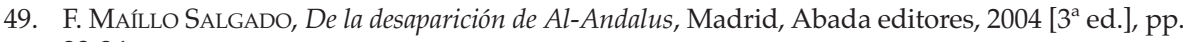
23-24. 
Para los musulmanes de Granada, la pérdida de la posición dominante se tradujo en la imposibilidad en la cual se encontraron, en adelante, de integrar cristianos en el Islam. El vencido se convierte a la religión del vencedor, sin reciprocidad. Era tan obvio, al entregarse la ciudad, que las peticiones de Boabdil y las capitulaciones mencionan solamente dos modalidades de paso de una religión a la otra: conversión al Islam antes, y conversión al Cristianismo después. Las cláusulas mencionan el caso en que una mujer cristiana, convertida al Islam y casada con un musulmán, quisiera volver a su religión anterior. Estas mujeres convertidas y casadas, que se llamaban romías, podían conservar algún apego a la fe de sus padres. Entre los musulmanes, se temía que el cambio de soberano se tradujera en presiones dirigidas, ante todo, hacia los musulmanes de origen cristiano, elches y romías, y hacia los hijos nacidos de estos matrimonios entre musulmanes de nacimiento y musulmanas por conversión. Es probablemente lo que incitó a Boabdil a pedir que los musulmanes por conversión fuesen protegidos legalmente contra las vejaciones y los insultos de los cristianos, y contra toda exigencia de retorno al Cristianismo. Concesión importante desde su punto de vista por cierto, Boabdil aceptó la posibilidad de retornos voluntarios al Cristianismo, bajo la condición de su control por testigos de ambas religiones:

"Yten, que todos los cristianos que se han tornado moros, machos ó hembras, que non ose ningund cristiano hazerles mal, ny deshonrarlos, y que non les pidan que se tornen cristianos, y el que lo hizier, que sea castigado, saluo el que quizier tornarse cristiano de su propia voluntad en presencia de los moros y de los cristianos ${ }^{\prime 50}$.

Además, la defección de las esposas musulmanas por conversión podía poner en peligro el poder del padre sobre sus hijos, fundamento de la estructura familiar y de la transmisión del Islam. Boabdil propuso que los hijos, en este caso, quedasen bajo la tutela de su padre. Si se aceptaba la posibilidad de su paso voluntario al Cristianismo, quedaba implícito que a estos hijos se les debía de considerar como musulmanes:

"Ytem, que el que tovier hijos de mugeres tornadizas, que quisieren de su voluntad tornarse á su ley, que los hijos queden para el padre, y que non los pida ningund cristiano para que se tornen cristianos, chicos ni grandes, sy non que sy quizier alguno tornarse de su voluntad, como dicho es, agora nin después de agora para siempre [Al margen: Ojo: fasta que fuesen de doze años]" ${ }^{\prime \prime 1}$.

Veamos ahora la respuesta de los Reyes Católicos a estas proposiciones. Se utilizó en parte el texto de Boabdil, reformulándolo. Los cristianos convertidos al Islam quedaban protegidos legalmente contre los insultos de los cristianos, pero se quitó la condición "y que non les pidan que se tornen cristianos":

50. Proposiciones, p. 234.

51. Ibídem, pp. 234-235. 
"Item es asentado e concordado que si algund cristiano ó cristiana se hobieren tornado moro ó mora en los tiempos pasados, ninguna persona sea osado de los amenguar nin baldonar en cosa alguna; y que si lo hicieren que sean castigados por sus Altezas" ${ }^{\prime 2}$.

En las capitulaciones, los elches no recibían ninguna garantía en cuanto a la conservación de su cualidad de musulmanes, porque nadie podía impedir que la Iglesia reivindicara sus derechos sobre unos individuos que, a sus ojos, eran cristianos apóstatas y no "moros y moras". La cláusula de garantía general contra las conversiones forzadas solo podía aplicarse a los que nunca habían recibido el bautismo, e incluso a los individuos cuyos padres y abuelos no eran cristianos. En aquella época se consideraba que una persona recibía su identidad de su linaje, lo cual prevalecía sobre sus opciones personales. La infidelidad religiosa se transmitía biológicamente, por la sangre: así se justificaba la noción de limpieza de sangre que conducía a excluir de ciertas funciones o de ciertos grupos de poder a los hijos y descendientes de judíos o de musulmanes convertidos. Todo esto es bastante conocido. A la inversa, la Iglesia consideraba que los hijos de cristianos eran miembros automáticamente de su jurisdicción, incluso cuando los padres cristianos eran apóstatas. Al principio del siglo XVII, el jesuita Francisco Suárez presenta esta norma como perfectamente establecida, en su reflexión sobre la licitud de administrar el bautismo a los hijos de los infieles que ya habían recibido el bautismo (siendo, entonces, apóstatas y no auténticos infieles):

"Es necesario considerar que estos infieles son sujetos directos de la Iglesia, en razón de su poder y jurisdicción espiritual: es el caso de todos los apóstatas quienes, después del bautismo, han hecho defección a la fe, o porque cayeron en la herejía, o porque pasaron al Judaísmo o al paganismo, y no hay controversia sobre su caso porque la Iglesia tiene el derecho de baptizar a sus hijos, incluso si ellos han renegado" ${ }^{\prime 53}$.

La cualidad de cristiano no dependía solamente del bautismo; era, finalmente, hereditaria. Se puede entender que la Iglesia consideraba como cristianos, o como individuos que debían ser reintegrados en las filas de los cristianos, incluso a unos musulmanes cuyos orígenes cristianos se remontaban a la generación de sus padres o de sus abuelos y que estaban totalmente integrados en la sociedad granadina anterior a la conquista.

52. Capitulaciones, p. 441

53. "Est enim considerandum, quosdam esse infideles, subditos Ecclesiae directe, ratione potestatis et juridictionis spiritualis; hujusmodi sunt omnes apostatae, qui post susceptum baptismum defecerunt a fide, sive in haeresim inciderint, sive in judaismum, aut paganismum declinaverint, et de his nulla est controversia, quin Ecclesia habeat jus baptizandi eorum infantes, etiam si parentes renituntur", F. SUÁREZ, Commentaria ac disputationes in tertiam partem D. Thomae [q. 68, art. 10] en Opera Omnia, t. XX, Paris, Louis Vives, 1860, pp. 420-446. 
En cuanto a las romías, la cláusula de las capitulaciones insistía en el carácter voluntario de su retorno al Cristianismo, punto que no se ponía en evidencia en la proposición de Boabdil:

"Item es asentado y concordado que si algund moro toviere alguna cristiana por muger que se haya tornado mora, que no la puedan tornar cristiana si su voluntad della; e que sea preguntada si quiere ser cristiana en presencia de cristianos e de moros; e que en lo de los hijos e hijas nacidos de las romías, se guarden los términos del derecho" ${ }^{\prime 54}$.

Tal vez se trataba de tranquilizar a las familias musulmanas cuya estabilidad no se pretendía amenazar, pero también de mostrar a las cristianas convertidas al Islam que, si querían volver a la Iglesia contra la voluntad de su familia política, podían obtener la ayuda de las autoridades. Insistimos en este punto: no se precisa, en las capitulaciones, que el retorno al Cristianismo de las otras categorías de convertidos (los hombres y las mujeres solteras) tiene que ser voluntario.

La frase que arregla la situación de los hijos requiere una explicación. Cuando Boabdil pedía que quedasen bajo el poder de su padre musulmán, la versión definitiva de la cláusula remite a "los términos del derecho". Las capitulaciones de Almería, otorgadas en febrero de 1490, estipulan "que los hijos nasçidos de las christianas no sean apremiados a tornarse christianos hasta que sean de doze años, y despues quede a su determinación de ser christianos o no" ${ }^{25}$, lo cual está claro. Pero la cláusula de Granada es muy diferente. No se debe suponer que aquí se remite al derecho musulmán sino al derecho canónico, ya que el caso implicaba a mujeres que eran cristianas según los criterios de la Iglesia. En los países cristianos, el derecho que se aplicaba en las causas matrimoniales era el de la Iglesia, el matrimonio siendo un sacramento y no un acto civil.

De antiguo, los canonistas habían arreglado el problema de los hijos nacidos de las uniones entre cristianos e infieles. Una de las autoridades en esta materia es un texto de 1229 conservado en las Decretales, el canon Ex Litteris, respuesta del papa Gregorio IX a una pregunta sobre la guarda del hijo de una pareja de judíos, después de la conversión del padre al Cristianismo. En este caso, el padre convertido pedía en justicia la guarda de su hijo a fin de darle una educación cristiana; mientras la madre judía fundaba su derecho a conservar a su hijo sobre los dolores del parto y los cuidados de la maternidad. Gregorio IX decidió en favor del padre, bajo el motivo que el hijo, habiendo pasado los tres años de edad, podía ser inducido por su madre en los errores de la infidelidad ${ }^{56}$. Antes del final del siglo XIII, los dos grandes canonistas de la época, el papa

\footnotetext{
54. Capitulaciones, p. 441.

55. “Capitulación de Almería, 11 de febrero de 1490”, en M.A. LADERo QuESADA, Granada..., apéndice documental n. 34, p. 410.

56. Decretales de Gregorio IX, 3.33.2.
} 
Inocencio IV y Enrique de Suso, cardinal de Ostia, aconsejaban decidir siempre en favor de la fe y, por consecuencia, confiar el hijo al que se había convertido. La dificultad era que, en caso de convertirse la madre, se quitaba al padre la patria potestas, una noción sacada del derecho romano y empleada como fundamento de la jerarquía familiar. El padre judío, según Enrique de Suso, gozaba de la patria potestas porque los matrimonios de los judíos se reconocían legalmente en el Imperio Romano, pero su infidelidad le incapacitaba a dar a su hijo la vida espiritual. En este caso, "la mujer debe tenerse por hombre, porque actúa virilmente" ${ }^{\prime 57}$, lo cual llevaba a confiarle la patria potestas. De todas formas, la religión tenía que ser el criterio determinante y, declaraba el canonista,

“Gregorio pudiera arreglar este asunto mas rápidamente, diciendo que si uno de dos cónyuges infieles se convirtiese a la fe, mientras el otro quedase en la infidelidad, los hijos pequeños se confiaran al convertido, excepto si tienen la edad de razón" ${ }^{58}$.

Estando establecida la doctrina desde aquella época, los comentaristas posteriores del canon Ex Litteris trataron otros aspectos del problema de la guarda de los hijos. Así se aclara el sentido de la cláusula de las capitulaciones: el padre musulmán cuya esposa volviese al Cristianismo no tenía posibilidad de obtener la guarda de sus hijos. La anotación "Ojo: fasta que fuesen de doze años" al margen del texto de Boabdil indica el límite de la edad de razón; tal vez se escribió en una primera redacción de la cláusula, que hubiese podido ser idéntica a la de las capitulaciones de Almería. Pero los redactores debieron de optar luego por una decisión menos favorable a los musulmanes.

No se puede considerar, entonces, que las capitulaciones de Granada establecieran el statu quo entre las dos religiones y que protegían a los elches contra las conversiones forzadas. Al contrario, dejaban a la Iglesia un amplio margen de acción para reintegrarlos en su seno. Nadie tenía derecho a insultarlos, pero en su cualidad de apóstatas podía perseguirlos el tribunal de la Inquisición, fundado en 1478 para castigar a los conversos de origen judío culpables de apostasía. En adelante, fueron las autoridades cristianas las que pretendieron definir la frontera entre los "moros y moras", musulmanes exentos de la jurisdicción eclesiástica por su condición de infieles, y los cristianos, entre los cuales, por supuesto, los apóstatas o elches estaban incluidos.

Pero los cristianos pasados al Islam y sus descendientes eran objeto de reivindicación tanto de parte de los cristianos como de los musulmanes. Los segundos consideraban que estos convertidos pertenecían a su comunidad de

57. "[...] debet mulier reputari vir, cum viriliter agat", E. de Suso, In Tertium Decretalium librum Commentaria, Venitiis, apud Iuntas, 1581, sobre X, 3.33.2.

58. "Potuisset ergo dominus Greg. hanc materiam plenius, brevius expedire, ut sic dixisset, si quis duorum coniugum infidelium ad fidem conversus fuerit, in infidelitate alio remanente, liberi infantes converso adiudicentur, doli tamen capaces suo iudicio relinquantur", ibídem. 
manera definitiva -excepto en el caso de defección voluntaria, excepción dictada por el realismo político en contra del derecho islámico-. Aceptar la pérdida de los elches y su afiliación a la Iglesia (o sea, su retorno a la infidelidad) equivalía a traicionar su propia convicción en la superioridad del Islam sobre las otras religiones. Así, la posición fronteriza de estos individuos se reveló una ocasión de conflicto entre los poderes cristianos y los musulmanes. Estos últimos entendieron la ofensiva de Cisneros hacia los elches como una conversión forzada y, por lo tanto, una violación flagrante de las capitulaciones.

Además, es posible que los granadinos no tuviesen un conocimiento muy preciso del contenido de las capitulaciones, lo que pudo acentuar el sentimiento de haber sido defraudados por los Reyes. Un texto de la primera mitad del siglo XVII, el libro octavo de la Historia de las dinastías musulmanas de AlMaqqari (un historiador originario de Tlemcen y considerado como bien informado), parece representativo de la lectura de las capitulaciones por parte de los musulmanes, una lectura más parecida a las proposiciones de Boabdil que a la redacción final de las cláusulas:

“El de rebi I del mismo año, es decir en año 897 (2 de enero de 1492), los cristianos tomaron posesión de la Alhambra [...]. La capitulaciones fueron sesenta y siete, entre ellas: [...] (2) que se mantendría su ley religiosa [šarī'a] como antes, y nadie les juzgaría sino por ella [...] (10) que no se obligaría a quien hubiese abrazado el islamismo a volver a los cristianos, ni a su religión (11) que al musulmán que hubiese abrazado el Cristianismo, se le dieran algunos días para que lo meditase, y habiéndolo citado un juez de los musulmanes y otro de los cristianos, si renunciara a volver al Islam, persistiría en lo que quisiera [...] (17) que nadie le impedirá llamar a la oración, ni rezar, ni ayunar, ni ninguna de las practicas de su culto, y que se castigaría a quien se mofase de éste" ${ }^{\prime 59}$.

El conflicto originado en las dos interpretaciones divergentes de las capitulaciones sobre la identidad de los elches estalló con la rebelión del Albaicín de finales de 1499. La deslealtad de las autoridades cristianas y el incumplimiento de lo pactado (actitudes inmorales que justificaban, una vez más, el desprecio de los musulmanes hacia los cristianos) fueron denunciados años después por Al-Maqqari:

"Pasado un tiempo los cristianos violaron el tratado y quebrantaron las capitulaciones, punto por punto, hasta que tornó la situación a exigirse de los musulmanes la conversión al Cristianismo en el año 904 (1499), después de [aducirse] motivos y razones, de las cuales la mayor y mas fuerte contra ellos era la siguiente: 'Los sacerdotes -decían- han dispuesto que todos los cristianos que hayan abrazado el Islam tienen que renegar a la fuerza de la infidelidad', y así lo tuvieron que hacer, aunque las gentes murmuraban, porque ya no tenían aguante ni vigor.

59. F.N. VELÁZQUEZ BASANTA, «La relación histórica sobre las postrimerías del Reino de Granada, según Ahmad al-Maqqarī (s. XVII)», en C. Del Moral (ed.), En el epilogo del Islam andalusí: la Granada del siglo XV, Granada, Universidad de Granada, 2002, pp. 535-537. 
Luego acudieron a otro expediente, que consistía en decir al creyente musulmán: 'Tu abuelo era cristiano y abrazó el Islam, pues hazte tu ahora cristiano'. Y cuando este inmoral procedimiento [se hizo insoportable], alzáronse los habitantes del Albaicín contra los esbirros de la justicia, y les dieron muerte, y éste fue el pretexto para [obligarlos] a la conversión diciendo: 'Ha venido orden el rey, que quien se haya rebelado contra la justicia ha de morir, a menos que [inmediatamente] se haga cristiano y se libre de la muerte" ${ }^{\prime \prime 60}$.

\section{CONCLUSIÓN}

Al final de la guerra de Granada, los Reyes no optaron por la expulsión de los musulmanes, si bien con el decreto de marzo de 1492 contra los judíos aportaron la prueba de que la evicción de una minoría religiosa se consideraba, a la sazón, como una medida de gobierno legítima. No siguieron la línea de un tratamiento radical de los vencidos, y prefirieron la vía de la negociación que les permitía mantener in situ a los habitantes del reino. Pero, entre las proposiciones presentadas por Boabdil para la entrega de Granada y el texto definitivo de las capitulaciones, los consejeros letrados de los Reyes debieron de realizar un importante trabajo de reflexión y de redacción. Las libertades religiosas otorgadas a los vencidos se quedaban dentro de los límites del derecho canónico, siendo la exención de señales distintivas la única derogación a éste, lo cual se entiende mejor como una concesión aceptada en la perspectiva de la conversión de los musulmanes que como un gesto de generosidad hacia las poblaciones conquistadas. Las capitulaciones otorgadas por los Reyes Católicos, cuyo celo de propagar la fe superaba la magnanimidad, establecían la dominación cristiana sobre el Islam. La reducción de los almuecines al silencio fue el símbolo de este nuevo orden político-religioso. La cláusula contra las conversiones forzadas, añadida por iniciativa de los Reyes para aquietar los ánimos de los vencidos, no ofrecía a éstos sino una protección muy precaria y que, de manera implícita, no se extendía a los descendientes de cristianos. En consecuencia, las capitulaciones dejaban largamente abierta la vía de la conversión por unos "medios blandos" que no excluían del todo ciertas presiones más recias.

$Y$ en efecto, los acontecimientos posteriores (desde los esfuerzos evangelizadores del arzobispo Talavera, hasta la política de captación de las élites con dádivas y favores que llevó el arzobispo Cisneros en el otoño de 1499) mostraron que los Reyes no contaban con una política de persecución masiva y sistemática para llevar a los musulmanes al bautismo. Hasta que los vencidos, que no pudieron sino considerar la empresa cisneriana de recuperación de los elches como una traición de lo pactado en 1491, tomaron las armas contra la autoridad real a finales de 1499 y cambiaron ipso facto de estatuto jurídico: ya

60. Ibídem, pp. 538-540. 
no eran los infieles pacíficos que, según el capítulo Dispar del Decreto, podían permanecer en paz en el territorio cristiano, sino unos sediciosos y rebeldes a los que se podía castigar con la muerte, la esclavitud o el exilio. Cediendo ante la fuerza superior de los ejércitos reales, los vencidos consintieron finalmente al bautismo que se les propuso -con magnanimidad, y para evitar la despoblación del reino- como condición de su perdón.

Hoy en día, nosotros vemos en estas conversiones una violación del principio de la libertad de conciencia (siendo los herederos de la reflexión de los teólogos, juristas y filósofos europeos de los siglos XVI-XVIII en este ámbito) y, además, una decisión política cargada de peligros, ya que sabemos lo que pasó después. Los contemporáneos cristianos las juzgaron según sus propios criterios. Para el arzobispo Cisneros, fue un acontecimiento providencial, una victoria de la fe, una anticipación de los tiempos mesiánicos. Para los juristas, la conversión de los granadinos después de las rebeliones de 1499-1501 fue una aplicación, entre otras, de la doctrina canónica sobre la recepción del bautismo en circunstancias de fuerza condicional. Como a los judíos convertidos bajo el reinado de Sisebuto, a los moriscos convenía en adelante "forzarlos a observar la fe que [habían] recibido por fuerza o por necesidad".

\section{RESUMEN}

El artículo propone una lectura de las cláusulas religiosas de las capitulaciones para la entrega de Granada (25 de noviembre de 1491). Se pone en tela de juicio la idea, comúnmente aceptada en la historiografía, de que las capitulaciones establecían el respeto a las leyes y a la religión de los vencidos y que, por lo tanto, las actuaciones que llevaron a la conversión de los musulmanes de Granada en los años 1499-1501 violaron las mismas capitulaciones. La comparación entre las peticiones del rey Boabdil y el texto firmado por los Reyes Católicos, apoyada sobre el derecho canónico, permite aclarar la posición de los Reyes en puntos tan decisivos como las modalidades del culto islámico, las señales de identificación, la prohibición de las conversiones forzadas y el estatuto de los hombres y mujeres convertidos del Cristianismo al Islam (elches). Se intenta demostrar que las capitulaciones, lejos de fijar la situación religiosa en Granada, establecían la dominación cristiana, abriendo el paso a una dinámica de conversión de la población musulmana y a la recuperación de los elches por la Iglesia.

Palabras clave: Granada, Reyes Católicos, capitulaciones, Islam, adhan, derecho canónico, conversiones forzadas.

\section{ABSTRACT}

The article proposes a reading of the religious clauses of the capitulations for the surrender of Granada ( 25 November 1491). It questions the idea, commonly 
accepted in historiography, that the capitulations established the respect to the laws and to the religion of the vanquished and that, therefore, the acts which led to the conversion of the Muslims of Granada in 1499-1501 violated the same capitulations. The comparison between the requests of king Boabdil and the text signed by the Catholic Kings clarifies, on the basis of canon law, the position of the Kings on such important issues as the modalities of Islamic cult, the distinctive signs of identification, the prohibition of forced conversions and the statute of men and women converted from Christianity to Islam (elches). It aims at showing that the capitulations, far from fixing the religious situation in Granada, established Christian domination and opened the way to a dynamics of conversion of the Muslims, and to the recovery of the elches by the Church.

Key words: Granada, Catholic Kings, capitulations, Islam, adhan, canon law, forced conversions. 